\title{
Phytochemical composition and antioxidant activity of 63 Balkan pepper (Capsicum annuum L.) accessions
}

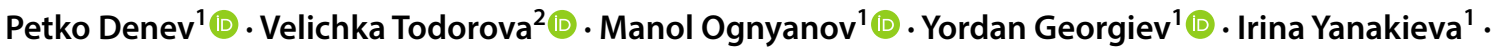 \\ Ivanka Tringovska ${ }^{2}$ (D) Stanislava Grozeva ${ }^{2}$ (i) $\cdot$ Dimitrina Kostova $^{2,3}$ (1)
}

Received: 3 December 2018 / Accepted: 27 May 2019

(c) Springer Science+Business Media, LLC, part of Springer Nature 2019

\begin{abstract}
In our study, we used the rich biodiversity of peppers in the Balkan region and characterized 63 pepper accessions from five cultivar types (Pungent; Sweet; Pumpkin; Kapia; For powder), in view of their phytochemical composition and antioxidant activity. The obtained results showed high variation in the compositional profiles between studied cultivar groups, as well within individual groups. Based on fresh weight (FW), the most abundant sugar in the studied accessions was glucose (0.36-3.79\%), followed by fructose (0.16-2.98\%). The accessions from "For powder" group were the richest source of uronic acids- $0.77 \%$, followed by accessions from "Pungent" group $-0.64 \%$. In four of the five groups, citric acid was the predominant organic acid, whereas only in the "Sweet" group, malic acid was the major representative of organic acid. The highest amount of ascorbic acid (Vitamin C) was found in a genotype CAPS-7, which is in the group of "Pungent" accessions. The polyphenol content varied in a broad range from $42 \mathrm{mg} / 100 \mathrm{~g} \mathrm{FW}$ to $266 \mathrm{mg} / 100 \mathrm{~g}$ FW. The differences in the flavonoid content were even more significant reaching 60 -fold difference-from $1.0 \mathrm{mg} / 100 \mathrm{~g} \mathrm{FW}$ to $64.3 \mathrm{mg} / 100 \mathrm{~g} \mathrm{FW}$. The accessions from the "For powder" group were leaders in regards to their total polyphenol and total flavonoid contents, as well as for their antioxidant activity, measured by ORAC and HORAC assays. This variation in fruit composition might be manipulated via plant breeding to create new pepper varieties with improved nutritional value of their fruits.
\end{abstract}

Keywords Capsicum annuum L. · Sugars · Organic acids $\cdot$ Polyphenols $\cdot$ Pectin $\cdot$ Antioxidant activity

\section{Introduction}

The sustainable food supply of growing population, the decrease of agricultural lands, climate changes and exhaustion of resources are among the major drivers of change in the twenty-first century. Fundamental transformations in agricultural systems are needed to assure enough healthy, safety and

artic supplementary material The online version of this article (https://doi.org/10.1007/s11694-019-00171-y) contains supplementary material, which is available to authorized users.

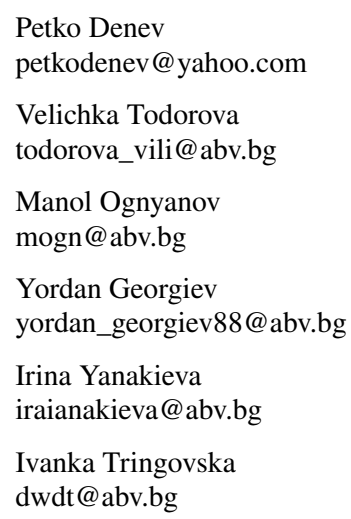

Stanislava Grozeva

stanislava_grozeva@abv.bg

Dimitrina Kostova

dkostova2011@gmail.com

1 Laboratory of Biologically Active Substances, Institute of Organic Chemistry with Centre of Phytochemistry, Bulgarian Academy of Sciences, 139 Ruski Blvd, 4000 Plovdiv, Bulgaria

2 Maritsa Vegetable Crops Research Institute, 32 Brezovsko shose Str, 4003 Plovdiv, Bulgaria

3 Center of Plant Systems Biology and Biotechnology, 139 Ruski Blvd, 4000 Plovdiv, Bulgaria 
cheap food, sustainable exploitation of biological resources, sustainable and competitive bioeconomy [1]. The characteristics of the current crop varieties do not meet or will not meet any longer the needs of producers, processors and consumers. In this respect, the leading task for the contemporary breeding is the creation of innovative varieties, combining high productivity and fruit quality, resistance to biotic and abiotic stress factors. Therefore, varieties that are more resilient and resource efficient, high yielding and with good fruit quality characteristics are needed. In addition, during the last decades, there has been an increased interest of consumers in a food with high nutritional quality. Attention is paid on phytonutrients in fruits and vegetables due to their antioxidant or anti-inflammatory effects [2-5].

Pepper (Capsicum annuum L.) is the most widely cultivated and economically important vegetable crop worldwide. Peppers are known to have high nutritional value of the fruits, but also have extremely diverse applications as food additives, health and cosmetic products, pest control agents in agricultural fields, etc. [6]. Tremendous diversity in fruit type, i.e. color, shape, pungency, flavor, size, and use, exists in $C$. anпиит L. [7]. The Balkan region is considered as a center of diversity for this crop, having its own endemic forms, unknown in other countries [8]. In view of the new priorities, this rich diversity is a unique biological resource, which could be exploited in future breeding programs. Pepper fruits are rich in biologically active substances as carotenoids, vitamins, flavonoids, fibers, microelements, etc. [9, 10]. The amount and composition of these secondary metabolites are affected by fruit maturity, cultivation systems, processing methods, etc. [11-14]. However, the differences in the genetic background contribute to the large variation in the biochemical composition of the pepper fruits [15]. Rich agro-biodiversity of peppers on the Balkan region is a valuable source of new alleles for improvement the quality and nutritional value of the fruits. To assist breeding programs, more insight is needed on fruit quality characteristics within large germplasm collections. Therefore, the aim of the study was to investigate the content of sugars, organic, acids, uronic acids, total polyphenols and flavonoids, as well as the antioxidant activity of 63 pepper (Capsicum annиum L.) accessions from the Balkans. Complex characterization of the different genotypes concerning fruit quality will add valuable data when choosing parent forms in the hybridization programs. Involvement of genotypes, rich in antioxidants, in the breeding programs will facilitate the increase of fruit quality and nutritional value of the future pepper varieties.

\section{Materials and methods}

\section{Chemicals}

Fluorescein (FL) disodium salt, 2,2-azobis-(2-amidinopropane)dihydrochloride (AAPH), 6-hydroxy-2,5,7,8tetramethylchroman-2-carboxylic acid (Trolox), gallic acid and quercetin dihydrate were obtained from Sigma-Aldrich (Steinheim, Germany). The Folin-Ciocalteu's phenol reagent was purchased from Merck (Darmstadt, Germany). All other solvents used were of analytical grade and purchased from local distributors.

\section{Plant material and growth conditions}

Totally 63 pepper accessions (all Capsicum annuиm L.) were selected from the Maritsa Vegetable Crops Research Institute (Maritsa VCRI) collection, based on differences in fruit color, shape, size, taste and usage. Genotypes were divided into five main groups: Pungent $(\mathrm{n}=8)$, Sweet (referred also as "Sweet green", $\mathrm{n}=22$ ), Pumpkin type $(\mathrm{n}=6)$, Kapia type $(\mathrm{n}=21)$ and sweet paprika for spice For powder $(\mathrm{n}=6)$. Plants were cultivated in an open field at Maritsa VCRI, Plovdiv, Bulgaria. Pepper seedlings, grown in a greenhouse, were transplanted in the middle of May on high flat bed. All accessions were grown in three replications, ten plants per replication, according to adopted technology for mid-early field production. Fertilization, irrigation, microclimate, etc. were the same for all genotypes. The experimental design was randomized complete block. The description of the genotypes, such as accession name, country of origin, population type, usage and fruit characters, is presented in Supplementary Table S1. The fruit features, such as pungency, shape, color and size of the 63 pepper accessions were determined according to Descriptors for Capsicum [16].

\section{Sampling and sample preparation}

Fruits from pepper genotypes were harvested in accordance with their usage: Pungent and Sweet green genotypes-before maturity (at intermediate stage of ripening), while others-at full ripening stage. Fruits were rinsed three times with distilled water and wiped. Half of them were freshly homogenized to mesh, which was used for analysis of dry matter by oven drying at $105^{\circ} \mathrm{C}$ to a constant weight. The rest were frozen at $-20^{\circ} \mathrm{C}$, freeze-dried, ground in a laboratory mill and stored at $-20{ }^{\circ} \mathrm{C}$ prior analysis. The lyophilized material was used for analysis of total flavonoid and polyphenol contents, carbohydrate 
and organic acids content and composition, uronic acids content and antioxidant activity.

\section{Extraction of polyphenols and flavonoids}

The extraction of polyphenols and flavonoids was performed according to Denev et al. [17]. Briefly, approximately $2 \mathrm{~g}$ of the freeze-dried peppers were weighted accurately, transferred to extraction tubes and mixed with $40 \mathrm{~mL}$ of the extragent ( $80 \%$ acetone solution in $0.5 \%$ formic acid). The extraction was carried out on an orbital shaker at room temperature for $1 \mathrm{~h}$. After that, the samples were centrifuged $(6000 \times g)$ and supernatants were further used for antioxidant activity determination and analysis of total polyphenols and flavonoids.

\section{Extraction of carbohydrates and organic acids}

The extraction of carbohydrates and organic acids was performed according to Denev et al. [17] with some modifications. Briefly, approximately $1 \mathrm{~g}$ of the freeze-dried peppers were weighted accurately and subjected to extraction with $30 \mathrm{~mL}$ distilled water for $1 \mathrm{~h}$ at $30^{\circ} \mathrm{C}$ and shaking on thermostatic water bath (NÜVE, Turkey). After that, the samples were centrifuged $(6000 \times g)$ and the supernatants were used for HPLC analysis of sugars and organic acids.

\section{High performance liquid chromatography (HPLC) analysis of sugars}

HPLC determination of sugars was performed on Agilent 1220 HPLC system (Agilent Technology, USA), equipped with binary pump and Refractive Index Detector (1260 RID). Separation was performed using Aminex HPX $-87 \mathrm{H}$ column $(300 \times 7.8 \mathrm{~mm}$, BioRad $)$, eluent $4 \mathrm{mM}$ $\mathrm{H}_{2} \mathrm{SO}_{4}$, flow $0.5 \mathrm{~mL} / \mathrm{min}$, temperature $25^{\circ} \mathrm{C}$. The standard compounds (glucose, fructose, xylose galactose, arabinose, sucrose and sorbitol) were purchased from Sigma-Aldrich (Steinheim, Germany). Results are expressed as g/100 g fresh weight $(\mathrm{FW})$.

\section{HPLC determination of organic acids}

HPLC determination of organic acids was performed on Agilent 1220 HPLC system (Agilent Technology, USA), equipped with binary pump and UV-Vis detector. Wavelength of $210 \mathrm{~nm}$ was used. Organic acid separation was performed using Agilent TC-C18 column $(5 \mu \mathrm{m}$, $4.6 \mathrm{~mm} \times 250 \mathrm{~mm}$ ) at $25{ }^{\circ} \mathrm{C}$. An isocratic elution with $25 \mathrm{mM}$ phosphate $\left(\mathrm{K}_{2} \mathrm{HPO}_{4} / \mathrm{H}_{3} \mathrm{PO}_{4}\right)$ buffer ( $\left.\mathrm{pH} 2.4\right)$, flowing at $0.8 \mathrm{~mL} / \mathrm{min}$ was used. Quinic acid, malic acid, ascorbic acid, shikimic acid, citric acid, $\alpha$-keto-glutaric acid, oxalic acid and tartaric acid used as standards were purchased from
Sigma-Aldrich (Steinheim, Germany). Results are expressed as $\mathrm{mg} / 100 \mathrm{~g} \mathrm{FW}$.

\section{Total polyphenol compounds analysis}

The total polyphenols were determined colorimetrically with the Folin-Ciocalteu's reagent according to the method of Singleton and Rossi [18]. Briefly, $0.1 \mathrm{~mL}$ of the extracts were mixed with $3.1 \mathrm{~mL}$ deionized water and $0.2 \mathrm{~mL}$ of Folin-Ciocalteu phenol reagents. After $3 \mathrm{~min}, 0.6 \mathrm{~mL}$ of $20 \%$ sodium carbonate was added to the mixture. Samples were incubated for $5 \mathrm{~min}$ at $50{ }^{\circ} \mathrm{C}$ and their absorbance was measured at $765 \mathrm{~nm}$. Gallic acid was employed as a calibration standard and the results were expressed as gallic acid equivalents (GAE) per $100 \mathrm{~g} \mathrm{FW}$.

\section{Total flavonoid content analysis}

The total flavonoid content was determined with $\mathrm{AlCl}_{3}$ reagent according to Chang et al. [19]. The calibration curve was constructed with quercetin dihydrate (10-200 mg/L). The results are expressed as mg quercetin equivalents $(\mathrm{QE})$ per $100 \mathrm{~g} \mathrm{FW}$.

\section{Total uronic acid content}

The uronic acid content in the initial plant material was determined as described by Ahmed and Labavitch [20]. Firstly, the freeze-dried plant material was incubated at $50{ }^{\circ} \mathrm{C}$ for $1 \mathrm{~h}$ with $70 \%(\mathrm{v} / \mathrm{v})$ aqueous ethanol and then the solids were separated by centrifugation $(14,000 \mathrm{rpm}, 10 \mathrm{~min}$, $\left.5{ }^{\circ} \mathrm{C}\right)$. The same procedure was repeated 3 times. Finally, the residue was washed 2 times with acetone at room temperature and vacuum-dried to obtain alcohol-insoluble solids (AIS). Before analysis the AIS samples were submitted to a prehydrolysis treatment with $72 \%(\mathrm{w} / \mathrm{w}) \mathrm{H}_{2} \mathrm{SO}_{4}$ for $1 \mathrm{~h}$ at $30{ }^{\circ} \mathrm{C}$, followed by a hydrolysis step with $1 \mathrm{M} \mathrm{H}_{2} \mathrm{SO}_{4}$ for $3 \mathrm{~h}$ at $100{ }^{\circ} \mathrm{C}$. The total uronic acid content in the hydrolyzates was assayed by colorimetric $m$-hydroxyl-diphenyl method according to Blumenkrantz and Asboe-Hansen [21]. The absorbance was measured at $520 \mathrm{~nm}$. UV-Visible ratio beam spectrophotometer HALO RB-10 (Dynamica, Australia) was used for the spectrophotometric measurements. Galacturonic acid $(5.0-80.0 \mu \mathrm{g} / \mathrm{mL})$ was used for the calibration curve and the results are expressed as $\mathrm{w} / \mathrm{w} \% \mathrm{FW}$.

\section{Oxygen radical absorbance capacity (ORAC) assay}

ORAC was measured according to the method of $\mathrm{Ou}$ et al. [22] with some modifications, described in details by Denev et al. [23]. Solutions of AAPH, fluorescein and trolox were prepared in a phosphate buffer $(75 \mathrm{mM}, \mathrm{pH}$ 7.4). Samples were diluted in the phosphate buffer as well. 
Reaction mixture (total volume $200 \mu \mathrm{L}$ ) contained FL$\left(170 \mu \mathrm{L}\right.$, final concentration $\left.5.36 \times 10^{-8} \mathrm{~mol} / \mathrm{L}\right), \mathrm{AAPH}-$ (20 $\mu \mathrm{L}$, final concentration $51.51 \mathrm{mM}$ ), and sample -10 $\mu \mathrm{L}$. The FL solution and sample were incubated at $37{ }^{\circ} \mathrm{C}$ for 20 min directly in a microplate reader, and AAPH (dissolved in buffer at $37{ }^{\circ} \mathrm{C}$ ) was added. The mixture was incubated for $30 \mathrm{~s}$ before the initial fluorescence was measured. After that, the fluorescence readings were taken at the end of every cycle ( $1 \mathrm{~min})$ after shaking. For the blank, $10 \mu \mathrm{L}$ of phosphate buffer was used instead of the extract. The antioxidant activity was expressed in micromole trolox equivalents ( $\mu \mathrm{mol} \mathrm{TE})$ per liter of extract. Trolox solutions $(6.25 ; 12.5 ; 25$ and $50 \mu \mathrm{mol} / \mathrm{L})$ were used for defining the standard curve. ORAC and HORAC analyses were carried out using a FLUOstar OPTIMA plate reader (BMG Labtech, Germany), excitation wavelength of $485 \mathrm{~nm}$ and emission wavelength of $520 \mathrm{~nm}$ were used. The results are expressed in micromole Trolox equivalents ( $\mu$ mol TE) per g FW.

\section{Hydroxyl radical averting capacity (HORAC) assay}

The HORAC assay measures the metal-chelating activity of antioxidants in the conditions of Fenton-like reactions employing a $\mathrm{Co}$ (II) complex and hence the protecting ability against formation of hydroxyl radical [2]. Hydrogen peroxide solution of $0.55 \mathrm{M}$ was prepared in distilled water. $4.6 \mathrm{mM}$ $\mathrm{Co}(\mathrm{II})$ was prepared as follows: $15.7 \mathrm{mg}$ of $\mathrm{CoF}_{2} \cdot 4 \mathrm{H}_{2} \mathrm{O}$ and $20 \mathrm{mg}$ of picolinic acid were dissolved in $20 \mathrm{~mL}$ of distilled water. FL $-170 \mu \mathrm{L}(60 \mathrm{nM}$, final concentration) and $10 \mu \mathrm{L}$ of sample were incubated in $37{ }^{\circ} \mathrm{C}$ for 10 min directly in the FLUOstar plate reader. After incubation $10 \mu \mathrm{L} \mathrm{H}_{2} \mathrm{O}_{2}$ (27.5 mM, final concentration) and $10 \mu \mathrm{L}$ of $\mathrm{Co}$ (II) $(230 \mu \mathrm{M}$ final concentration) solutions were added subsequently. The initial fluorescence was measured after which the readings were taken every minute after shaking. For the blank sample, phosphate buffer solution was used. 100, 200, 600, 800 and $1000 \mu \mathrm{M}$ gallic acid solutions (in phosphate buffer $75 \mathrm{mM}$, $\mathrm{pH}$ 7.4) were used for building the standard curve. The area under the curves were calculated as they were for the ORAC. The results are expressed in micromole gallic acid equivalents ( $\mu$ mol GAE) per gram FW.

\section{Statistical analysis}

Results were presented as mean \pm standard deviation (SD) from at least three different measurements. The intergroup comparison was made with one-way analysis of variance (ANOVA). When significant, the results were compared by Duncan Multiple Range Test. P-values less than 0.05 were considered significant.

\section{Results and discussion}

\section{Sugar, organic acid and uronic acid content}

In view of the priorities of contemporary breeding, the agricultural biodiversity is considered as an important source of new alleles for development of improved varieties with valuable traits. The characterization of agrobiodiversity in certain regions is also a strategy for preservation and better exploitation of the germplasm [24, 25]. In our study, we used the rich biodiversity of peppers on the Balkan region and characterized 63 pepper accessions in view of the phytochemical composition of their fruits. Accessions were preliminary grouped according to their cultivar type-_Pungent" and "Sweet" were harvested before maturity, while "Pumpkin", "Kapia" and "For powder"-at maturity stage.

The content and composition of soluble sugars in the plant foods are very important for their nutritional value and taste profile and therefore determining for the customers' preferences. The content and composition of sugars in the investigated pepper accessions are presented in Supplementary Table S2. As it is evident, the accessions differ in their sugar content and composition. The total content of the investigated sugars varies in the range $1.09-7.38 \%$ and in most of the studied samples, glucose $(0.36-3.79 \%)$ is the main sugar, followed by fructose $(0.16-2.98 \%)$. These two sugars were detected in all investigated samples. There were several exceptions, such as CAPS-6 and CAPS-12, where sucrose was the predominant sugar. Interestingly, Jamiołkowska et al. [26] did not find any significant differences in the amount of glucose and fructose in 3 harvests of sweet peppers (cultivar Roberta $F_{1}$ ), as similarly to our findings sucrose was detected in minor amounts. In quantifiable amounts, sucrose was found mostly in "Pungent" and "Sweet green" groups, which is probably related to the fruit maturity, since fruits in these groups are harvested before maturity. Similarly to other authors [27, 28], we attribute some differences in the carbohydrate profiles to the stage of maturity. Several accessions (CAPS-8, -16, $-23,-27,-33,-44,56,-66)$ from the five studied groups had comparatively high level of total soluble neutral sugars. This suggests them as possible candidates for selection for a sweeter taste. Glucose and fructose contents normally increase during fruit ripening, while sucrose is decreased [27]. Interestingly, besides glucose, fructose and sucrose, we found that some of the analyzed accessions contained also xylose, rhamnose and galactose. Arabinose was only detected in trace amounts in several accessions. The accession CAPS-44 from "Kapia" group had total soluble neutral sugar content $7.38 \%$, which is 2 - to 3 -fold higher than the other accessions within the three groups. The other 
accessions, distinguished with higher total sugars content are CAPS-33 (4.47\%), CAPS-56 (4.49\%) and CAPS-66 $(3.95 \%)$.

The carbohydrate profiles of the tested groups are graphically presented in Fig. 1. As it could be seen from the results, studied groups differ significantly in their sugar profiles. For example, sucrose could be found in substantial quantities in "Pungent" and "Sweet green" groups, whereas xylose is characteristic for "Kapia" and "For powder" groups. "Pumpkin", "Kapia" and "For powder" accessions were distinctive with the high content of galactose. Contrary, rhamnose was more abundant in "Pungent", "Sweet green" and "Pumpkin" groups. Xylose, galactose and rhamnose are expected to originate from the partly enzymatic degradation of cell wall polysaccharides, such as hemicelluloses and pectins during maturation. The groups "Pungent" and "Green", which are harvested before maturity, were with lower contents of glucose, fructose and total soluble sugars, compared to the other three groups. Among the accessions, CAPS- 8 from the "Pungent" group and CAPS-16, CAPS-23 and CAPS27 from the "Sweet green" group have the highest values for total soluble neutral sugars. Although the differences found within accessions from each group, average values for "Pumpkin", "Kapia" and "For powder" do not differ significantly for their total soluble neutral sugar content.

The detected uronic acids in the AIS of the peppers indicates the presence of pectic polysaccharides, which are complex heteropolysaccharides mainly occurring in the primary cell wall. Pectin is mostly composed of homogalacturonans, xylogalacturonans, rhamnogalacturonans type I, and rhamnogalacturonans type II [29]. Pectic polysaccharides are widely used in food industry for their valuable thickening properties. Besides, they reveal numerous biologically activities, thus increasing the nutritional value of plant foods. Consumption of this fiber has been linked to positive health benefits, such as cholesterol-lowering, immunomodulating, cancer-preventing, and plasma glucose-regulating effects
[30]. The content of total uronic acids found in the samples is presented in Supplementary Table S2. The average values for every group show that the accessions from "For powder" group are the richest source of uronic acids- $0.77 \%$, followed by accessions from "Pungent" group $-0.64 \%$. The rest three groups do not differ significantly between each other. Our results for uronic acid content for some of the chili accessions (CAPS-6, -7, -8) were in agreement with these reported by Lopez-Hernindez et al. [31] for the Spanish variety Longum of Capsicum annuит, L. (0.73\%). An elevated dry matter content is of interest to the food industry since it is responsible for a higher fruit yield in the food processing. In the groups of "Pumpkin", "Kapia" and "For powder", which are suitable for possessing, the accessions with outstanding levels of dry matter are CAPS-33 (11.1\%), CAPS-44 (15.2\%) and CAPS-65 (16.7\%), respectively.

Organic acids in foods are another important component that contributes to their palatability. Data on the organic acids content and composition of the studied pepper accessions are presented in Supplementary Table S3. Seven from the investigated eight organic acids (oxalic acid, tartaric acid, quinic acid, malic acid, ascorbic acid, $\alpha$-ketoglutaric acid, citric acid, succinic acid) were detected in almost all accessions. The predominant ones were citric, malic and quinic acids, while the least distributed was succinic acid. Similarly, Jarret et al. [32] determined that citric $(244.2 \mathrm{mg} / 100 \mathrm{~g} \mathrm{FW})$ and malic $(69.5 \mathrm{mg} / 100 \mathrm{~g} \mathrm{FW})$ acids were the main organic acids in Capsicum chinense. Luning [27] showed that malic acid was predominant in the green bell peppers, and citric acid was in the mature red stage. Furthermore, quinic acid was also quantified in representable amounts by López-Hernández et al. [31] in C. annum L . (Longum). Interestingly, some authors reported the presence of fumaric acid, which was not found in our accessions [31, 32]. The overall organic acid content of the studied accessions, expressed as the sum of the individual representatives varied between $135 \mathrm{mg} / 100 \mathrm{~g}$ and $708 \mathrm{mg} / 100 \mathrm{~g}$.
Fig. 1 Average distribution of different sugars among the studied groups

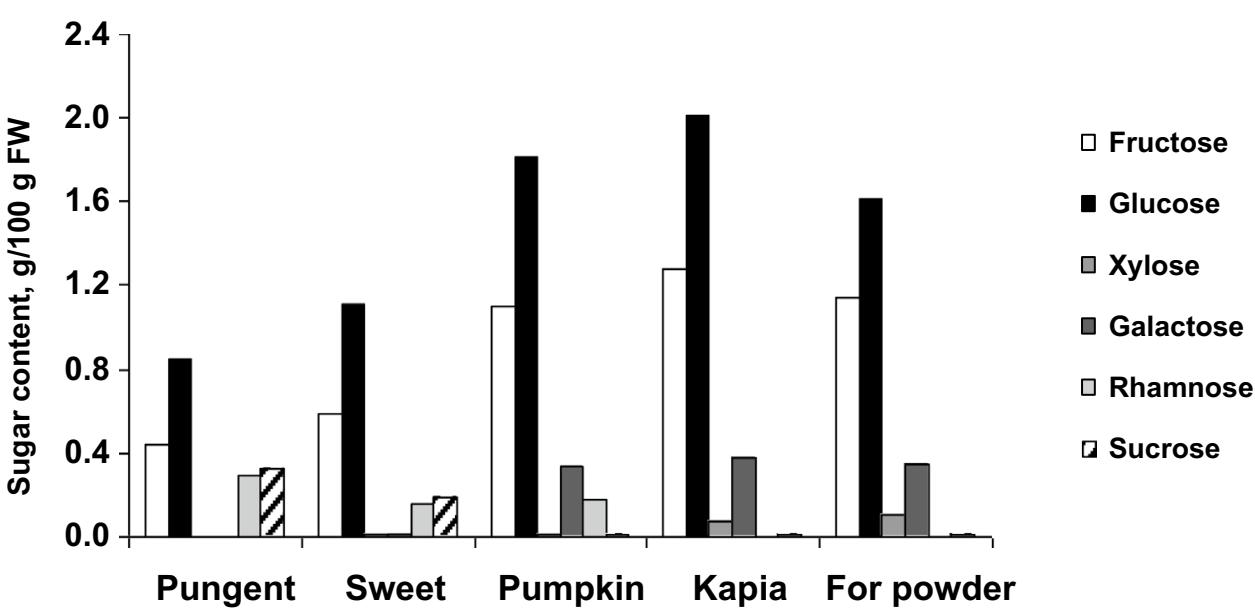


Similarly, to the sugar content, the organic acid profile of different groups differed significantly (Fig. 2). In four of the five groups, citric acid was the predominant representative, whereas only in the "Sweet green" group, malic acid was the major organic acid. The amount of this acid was higher in "Pungent" and "Sweet green" accessions than in other groups, which probably is again due to the stage of fruit maturity. For example, accessions from "Sweet green" and "Pungent" groups, which were harvested before maturity, have lower total content of organic acids than the other three groups, which were harvested at maturity stage. This is in agreement with other authors, who have observed that the content of organic acids increases with ripening $[33,34]$.

From the studied organic acids, ascorbic acid, known as vitamin $\mathrm{C}$ is an essential antioxidant and a cofactor for enzymes involved in the human metabolism. It is known that Capsicum fruits are physiologically relevant source of vitamin $\mathrm{C}$ and may contribute $50 \%$ to over $100 \%$ of the recommended daily intake of vitamin C $[35,36]$. In our study, ascorbic acid content varied in the range 7-92 mg/100 g FW. The highest amount of vitamin $\mathrm{C}$ is found in CAPS-7 genotype, which is in the group of pungent accessions. Other authors also observed that hot pepper cultivars were richer in vitamin $\mathrm{C}$, than the sweet ones [37]. However, fruit maturity strongly affects the content of vitamin $\mathrm{C}$, as well $[38,39]$. In the group of green sweet pepper accessions, vitamin $\mathrm{C}$ varied from 12.4 (CAPS-30) to 34.8 (CAPS-14) mg/100 g FW. In the groups of "Pumpkin", "Kapia" and "For powder" the highest vitamin $\mathrm{C}$ levels were found in CAPS-34 (55.8 mg/100 g FW), CAPS-44 (77.8 mg/100 g FW) and CAPS-67 (42.2 mg/100 g FW), respectively. Similarly, large variation of ascorbic acid content between genotypes is detected in large collections of C. annuиm, C. baccatum, C. chinense and other Capsicum species [32, 40].

Figure 3 presents the summarized data for the content of soluble neutral sugars, organic acids and uronic acids in the investigated 63 pepper accessions. Although the relatively high standard deviations, which could be explained with the large number of samples, there are significant differences among the studied groups. For example, the soluble neutral sugar content of "Pumpkin", "Kapia" and "For powder" groups are significantly higher than those for "Pungent" different organic acids among the studied groups
Fig. 2 Average distribution of

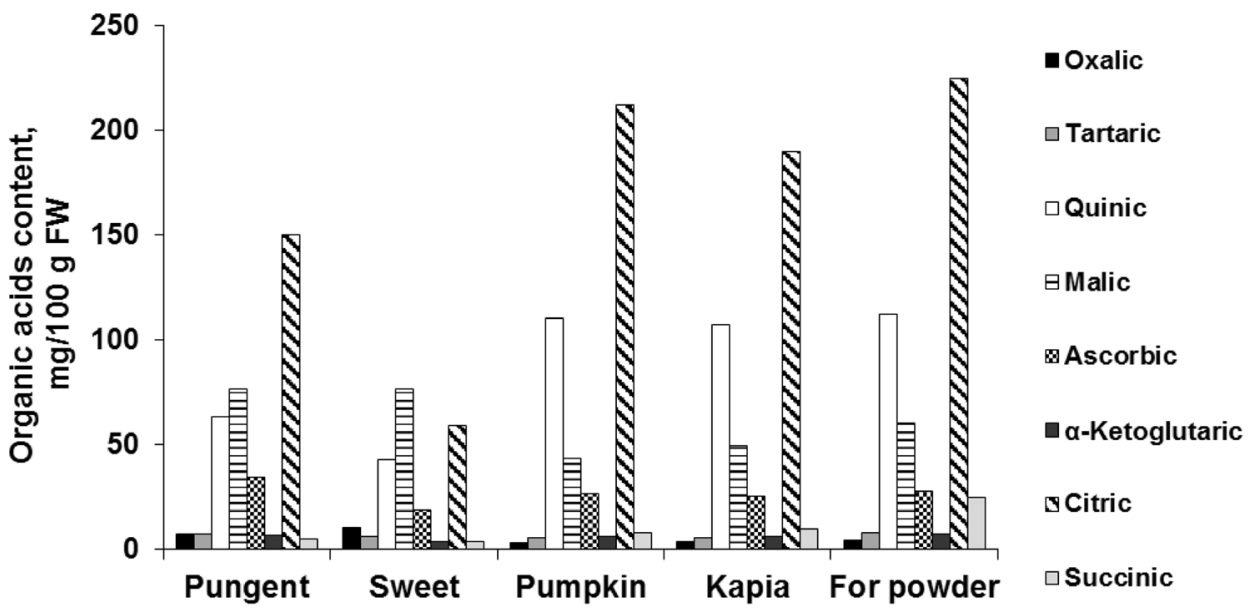

Fig. 3 Sugar, organic acid and uronic acid content of the studied groups. Results are expressed as mean value for the group $\pm \mathrm{SD}$. There are no significant differences among values marked with the same letters in individual groups

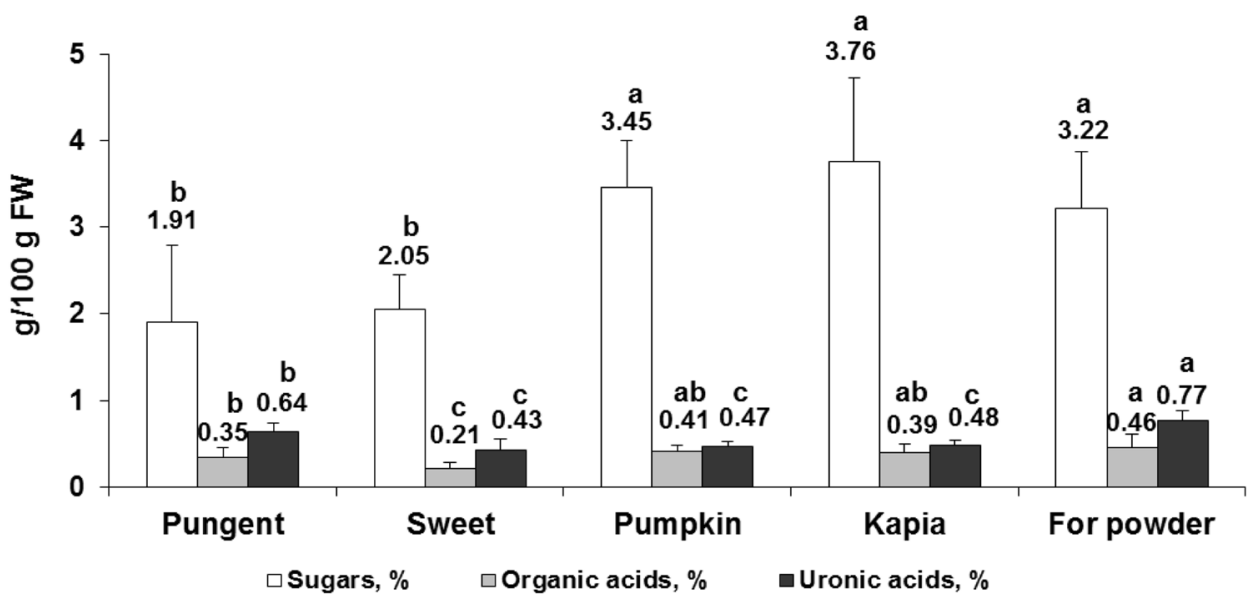


and "Sweet green". In regards to the total uronic acids, "For powder" group is distinctive with the highest content as was mentioned above. From Supplementary Table S2, it is clear that the dry matter content of "For powder" representatives is the highest compared to the rest accessions, which could explain the highest content of uronic acids in that particular group. It is well known that uronic acid content represents the amount of pectic polysaccharides in the plant cell. Therefore, the high content of dry matter in "For powder" group could be related to higher content of pectic polysaccharides and hence higher uronic acid content.

\section{Polyphenol and flavonoid contents and antioxidant activity}

Polyphenols, including flavonoids are secondary metabolites that are synthesized mainly in plants. It is known that these components protect plants from pathogens, UV-B light and play role as signal molecules in the interaction between plants and environment [41, 42]. Polyphenolic compounds gained significant attention because they act as antioxidants and protect human body from the oxidative stress, which is the main reason for different degenerative processes. Because of the polyphenol components, the consumption of fruits and vegetables is reversely correlated with the development of chronic diseases [43]. Due to their health benefits, polyphenols are particularly desired components, especially in vegetables like peppers that are consumed in big amounts worldwide. Many factors could influence the accumulation of polyphenols in plants, such as genotype, light, temperature, etc. Therefore, contemporary breeding programs are directed to the selection of cultivars with increased content of polyphenols and other antioxidant components [44]. Table 1 presents the results for total polyphenol and total flavonoid contents of the investigated accessions, as well as their antioxidant activity, measured by ORAC and HORAC methods. From the results, it is evident that the polyphenol content varies in a broad range from $42 \mathrm{mg} / 100 \mathrm{~g} \mathrm{FW}$ (CAPS-18) to more than sixfold higher value of $267 \mathrm{mg} / 100 \mathrm{~g} \mathrm{FW}$ (CAPS-64 and CAPS-67). The differences in the flavonoid content of the accessions are even more drastic, reaching 60 -fold difference-from $1.0 \mathrm{mg} / 100 \mathrm{~g} \mathrm{FW}$ (CAPS-28) to $64.3 \mathrm{mg} / 100 \mathrm{~g}$ FW (CAPS-14). Various flavonoids and phenolic acids have been identified in different Capsicum annиum L. cultivars. The major representatives are hydroxycinnamic derivatives, quercetin, luteolin and their $O$-glycosides. Besides, chrysoeriol $O$-glycosides and $C$-glycosyl flavones were reported as minor components [45, 46].

Interestingly, there are significant differences in the studied groups both in their polyphenol and flavonoid contents (Fig. 4). The accessions from the "For powder" group are leaders in regards to their total polyphenol and total flavonoid contents, whereas "Sweet green" group accessions are the poorest source of polyphenols and "Pumpkin" are the poorest source of flavonoids.

In our study, we used two complementary methods for antioxidant activity determination-ORAC and HORAC. ORAC method is an indicator of the free-radical scavenging ability of antioxidants against peroxyl radical, using the mechanism of hydrogen atom transfer. On the other hand, HORAC measures the metal-chelating properties of antioxidants, thereby expressing a radical prevention ability of the sample. Using more than one method for antioxidant activity determination is recommended since it gives more comprehensive picture of the antioxidant potential of the tested sample [47]. In comparison to other fruits [48] and vegetables [47], peppers are relatively low in their content of antioxidants but the significant amounts that could be taken with a single meal make them physiologically relevant source of antioxidants. Usually, there is a good correlation between the content of total polyphenols and antioxidant activity of the plant foods $[4,34]$. Therefore, we expected that the differences in the polyphenol content of the investigated accessions would result in differences in the antioxidant activity. For example, accession CAPS-18 had an ORAC value of $3.58 \pm 0.15 \mu \mathrm{mol}$ TE/g FW, whereas CAPS-67 showed an ORAC value of $30.53 \pm 1.73 \mu \mathrm{mol} \mathrm{TE} / \mathrm{g}$ FW. This sample had the highest antioxidant activity $(14.73 \pm 0.47 \mu \mathrm{mol}$ GAE/g FW), measured by the HORAC method, as well. The antioxidant capacity assays measure the combined effect of many antioxidants present in the sample, which are able to scavenge free radicals, generated in the assays. Therefore, antioxidant activity of a plant material depends on the antioxidant activities of its individual antioxidants, as well as the possible interactions (synergism, antagonism and additivism) between them. As it is evident from the table, some samples with high flavonoid content do not necessarily show high antioxidant activity. This is probably due to the different flavonoid representatives in these samples, since individual flavonoids could differ significantly in their antioxidant activities. For example, depending on the used assay, quercetin reveals 2 to 3 -fold-higher antioxidant activity in comparison to its glycoside rutin [49].

Figure 5 compares the mean values of antioxidant activity of the studied groups. Similarly to the polyphenol content, the "For powder" group was on the first place both by ORAC and HORAC values and differed significantly from the rest groups. "Sweet green" and "Pungent" groups were the two groups that revealed the lowest antioxidant activity. These results could be explained by the fact that the fruits from the groups "For powder", "Kapia" and "Pumpkin" were harvested and evaluated at maturity stage and the content of secondary metabolites with antioxidant activity is much higher. 
Table 1 Total polyphenol and flavonoid content, ORAC and HORAC antioxidant activity of pepper accessions

\begin{tabular}{|c|c|c|c|c|}
\hline Sample & $\begin{array}{l}\text { Total polyphenols, mg } \\
\text { /100 g FW }\end{array}$ & $\begin{array}{l}\text { Total flavonoids, } \\
\mathrm{mg} / 100 \mathrm{~g} \text { FW }\end{array}$ & $\begin{array}{l}\text { ORAC, } \\
\mu \mathrm{mol} \text { TE/g FW }\end{array}$ & $\begin{array}{l}\text { HORAC, } \\
\mu \mathrm{mol} \text { GAE/g FW }\end{array}$ \\
\hline CAPS-2 & $121.8 \pm 6.0$ & $19.4 \pm 1.6$ & $11.44 \pm 1.37$ & $2.86 \pm 0.22$ \\
\hline CAPS-4 & $132.0 \pm 7.8$ & $14.9 \pm 0.6$ & $11.18 \pm 0.36$ & $3.02 \pm 0.12$ \\
\hline CAPS-5 & $133.1 \pm 5.4$ & $10.0 \pm 1.9$ & $11.92 \pm 0.84$ & $3.22 \pm 0.25$ \\
\hline CAPS-6 & $147.5 \pm 3.8$ & $12.6 \pm 1.0$ & $13.89 \pm 0.68$ & $5.06 \pm 0.20$ \\
\hline CAPS-7 & $149.2 \pm 1.6$ & $10.8 \pm 1.0$ & $14.85 \pm 0.58$ & $2.82 \pm 0.18$ \\
\hline CAPS- 8 & $116.7 \pm 5.1$ & $10.8 \pm 0.9$ & $9.82 \pm 0.80$ & $2.85 \pm 0.29$ \\
\hline CAPS-9 & $109.5 \pm 3.6$ & $23.9 \pm 0.8$ & $7.95 \pm 0.71$ & $1.59 \pm 0.16$ \\
\hline CAPS-10 & $71.5 \pm 2.1$ & $18.8 \pm 0.2$ & $6.11 \pm 0.13$ & $1.10 \pm 0.06$ \\
\hline CAPS-11 & $233.8 \pm 4.0$ & $10.0 \pm 1.4$ & $18.77 \pm 0.87$ & $5.09 \pm 0.26$ \\
\hline CAPS-12 & $188.5 \pm 2.4$ & $20.2 \pm 0.8$ & $16.30 \pm 1.53$ & $3.26 \pm 0.21$ \\
\hline CAPS-13 & $121.4 \pm 1.1$ & $21.8 \pm 0.4$ & $10.95 \pm 1.00$ & $2.64 \pm 0.30$ \\
\hline CAPS-14 & $153.6 \pm 7.2$ & $64.3 \pm 1.8$ & $13.81 \pm 1.76$ & $3.65 \pm 0.54$ \\
\hline CAPS-15 & $99.3 \pm 0.6$ & $10.4 \pm 1.0$ & $8.38 \pm 0.74$ & $2.28 \pm 0.21$ \\
\hline CAPS-16 & $85.8 \pm 1.7$ & $9.8 \pm 0.2$ & $9.25 \pm 0.68$ & $2.51 \pm 0.22$ \\
\hline CAPS-17 & $60.6 \pm 0.7$ & $19.4 \pm 1.3$ & $5.64 \pm 0.57$ & $2.09 \pm 0.16$ \\
\hline CAPS-18 & $42.1 \pm 1.0$ & $9.5 \pm 0.9$ & $3.58 \pm 0.15$ & $0.97 \pm 0.10$ \\
\hline CAPS-19 & $81.8 \pm 4.3$ & $23.7 \pm 0.1$ & $6.58 \pm 0.28$ & $2.43 \pm 0.08$ \\
\hline CAPS-20 & $66.3 \pm 0.7$ & $7.4 \pm 0.7$ & $6.07 \pm 0.56$ & $1.81 \pm 0.09$ \\
\hline CAPS-21 & $87.0 \pm 4.5$ & $13.6 \pm 0.6$ & $7.95 \pm 0.79$ & $2.98 \pm 0.14$ \\
\hline CAPS-22 & $80.9 \pm 1.7$ & $8.3 \pm 0.6$ & $7.47 \pm 0.59$ & $3.11 \pm 0.16$ \\
\hline CAPS-23 & $120.7 \pm 0.0$ & $27.1 \pm 1.3$ & $11.64 \pm 0.40$ & $3.66 \pm 0.12$ \\
\hline CAPS-24 & $83.6 \pm 0.2$ & $18.7 \pm 0.2$ & $8.43 \pm 0.56$ & $2.99 \pm 0.15$ \\
\hline CAPS-25 & $69.1 \pm 4.5$ & $9.4 \pm 0.2$ & $6.30 \pm 0.57$ & $2.33 \pm 0.16$ \\
\hline CAPS-26 & $90.7 \pm 2.8$ & $11.9 \pm 0.8$ & $7.33 \pm 0.77$ & $1.75 \pm 0.13$ \\
\hline CAPS-27 & $59.3 \pm 3.9$ & $5.9 \pm 0.1$ & $5.70 \pm 0.21$ & $2.34 \pm 0.13$ \\
\hline CAPS-28 & $47.3 \pm 0.6$ & $1.0 \pm 1.1$ & $4.67 \pm 0.36$ & $1.66 \pm 0.06$ \\
\hline CAPS-29 & $96.4 \pm 0.1$ & $8.9 \pm 0.2$ & $8.74 \pm 0.38$ & $3.10 \pm 0.10$ \\
\hline CAPS-30 & $78.5 \pm 3.5$ & $4.4 \pm 0.6$ & $6.59 \pm 0.46$ & $1.78 \pm 0.13$ \\
\hline CAPS-31 & $103.7 \pm 1.8$ & $6.8 \pm 0.6$ & $8.00 \pm 0.61$ & $2.84 \pm 0.12$ \\
\hline CAPS-32 & $58.8 \pm 0.2$ & $11.5 \pm 0.9$ & $5.73 \pm 0.32$ & $2.36 \pm 0.12$ \\
\hline CAPS-33 & $162.6 \pm 0.3$ & $12.9 \pm 0.3$ & $10.97 \pm 0.24$ & $5.16 \pm 0.26$ \\
\hline CAPS-34 & $143.5 \pm 4.0$ & $11.1 \pm 0.4$ & $13.78 \pm 1.07$ & $7.03 \pm 0.29$ \\
\hline CAPS-35 & $171.9 \pm 0.4$ & $5.8 \pm 0.0$ & $17.07 \pm 0.49$ & $7.04 \pm 0.14$ \\
\hline CAPS-36 & $151.5 \pm 4.0$ & $12.1 \pm 0.8$ & $12.45 \pm 0.65$ & $5.79 \pm 0.18$ \\
\hline CAPS-37 & $103.2 \pm 1.9$ & $3.2 \pm 0.6$ & $10.59 \pm 0.22$ & $4.25 \pm 0.06$ \\
\hline CAPS-38 & $148.5 \pm 0.6$ & $11.1 \pm 0.4$ & $16.25 \pm 0.47$ & $6.67 \pm 0.16$ \\
\hline CAPS-39 & $127.1 \pm 3.0$ & $6.5 \pm 0.2$ & $11.06 \pm 0.47$ & $4.31 \pm 0.14$ \\
\hline CAPS-40 & $172.2 \pm 4.4$ & $23.9 \pm 1.2$ & $14.21 \pm 0.78$ & $7.11 \pm 0.26$ \\
\hline CAPS-41 & $171.1 \pm 1.8$ & $14.0 \pm 0.5$ & $13.62 \pm 0.45$ & $6.98 \pm 0.15$ \\
\hline CAPS-42 & $89.4 \pm 1.7$ & $7.9 \pm 0.3$ & $9.74 \pm 0.28$ & $3.90 \pm 0.10$ \\
\hline CAPS-44 & $241.4 \pm 4.5$ & $13.8 \pm 1.0$ & $24.43 \pm 1.98$ & $11.48 \pm 0.54$ \\
\hline CAPS-45 & $163.9 \pm 0.6$ & $7.9 \pm 0.2$ & $18.62 \pm 0.36$ & $7.47 \pm 0.26$ \\
\hline CAPS-46 & $187.3 \pm 1.5$ & $11.7 \pm 1.2$ & $19.04 \pm 0.64$ & $9.56 \pm 0.17$ \\
\hline CAPS-47 & $112.4 \pm 4.8$ & $8.3 \pm 0.1$ & $13.71 \pm 0.30$ & $5.50 \pm 0.28$ \\
\hline CAPS-48 & $131.4 \pm 3.4$ & $9.1 \pm 0.0$ & $12.00 \pm 0.70$ & $5.04 \pm 0.20$ \\
\hline CAPS-49 & $112.6 \pm 4.4$ & $7.8 \pm 0.3$ & $13.78 \pm 0.83$ & $5.49 \pm 0.28$ \\
\hline CAPS-50 & $134.9 \pm 3.5$ & $4.1 \pm 2.8$ & $13.05 \pm 0.45$ & $5.06 \pm 0.12$ \\
\hline CAPS-52 & $119.6 \pm 3.5$ & $14.0 \pm 1.4$ & $11.74 \pm 0.31$ & $4.08 \pm 0.15$ \\
\hline CAPS-53 & $161.1 \pm 4.0$ & $14.2 \pm 0.6$ & $11.22 \pm 0.13$ & $4.63 \pm 0.12$ \\
\hline CAPS-54 & $168.5 \pm 0.8$ & $12.8 \pm 1.1$ & $15.09 \pm 0.32$ & $6.05 \pm 0.24$ \\
\hline
\end{tabular}


Table 1 (continued)

Fig. 4 Total polyphenol and flavonoid contents of the studied groups. Results are expressed as mean value for the group $\pm \mathrm{SD}$. There are no significant differences among values marked with the same letters in individual groups

\begin{tabular}{llllc}
\hline Sample & $\begin{array}{l}\text { Total polyphenols, } \mathrm{mg} \\
\text { /100 g FW }\end{array}$ & $\begin{array}{l}\text { Total flavonoids, } \\
\mathrm{mg} / 100 \mathrm{~g} \mathrm{FW}\end{array}$ & $\begin{array}{l}\text { ORAC, } \\
\mu \mathrm{mol} \text { TE/g FW }\end{array}$ & $\begin{array}{l}\text { HORAC, } \\
\mu \mathrm{mol} \text { GAE/g FW }\end{array}$ \\
\hline CAPS-55 & $148.9 \pm 0.6$ & $17.1 \pm 1.1$ & $16.94 \pm 0.80$ & $8.04 \pm 0.22$ \\
CAPS-56 & $153.8 \pm 2.0$ & $13.4 \pm 1.1$ & $16.25 \pm 0.64$ & $6.75 \pm 0.37$ \\
CAPS-57 & $117.7 \pm 1.4$ & $5.9 \pm 0.3$ & $11.55 \pm 0.97$ & $5.21 \pm 0.26$ \\
CAPS-58 & $216.1 \pm 3.3$ & $13.6 \pm 0.3$ & $20.10 \pm 0.27$ & $9.47 \pm 0.54$ \\
CAPS-59 & $111.4 \pm 6.2$ & $10.7 \pm 0.2$ & $13.09 \pm 1.00$ & $5.22 \pm 0.27$ \\
CAPS-60 & $118.1 \pm 1.2$ & $13.6 \pm 0.4$ & $13.33 \pm 1.28$ & $5.87 \pm 0.35$ \\
CAPS-61 & $120.8 \pm 0.3$ & $12.5 \pm 0.4$ & $12.35 \pm 0.43$ & $5.18 \pm 0.24$ \\
CAPS-62 & $141.4 \pm 1.1$ & $18.0 \pm 0.8$ & $17.53 \pm 1.21$ & $7.89 \pm 0.33$ \\
CAPS-63 & $150.3 \pm 0.8$ & $12.0 \pm 1.0$ & $19.14 \pm 0.96$ & $9.34 \pm 0.26$ \\
CAPS-64 & $266.6 \pm 6.1$ & $14.0 \pm 1.0$ & $22.46 \pm 0.41$ & $10.56 \pm 0.30$ \\
CAPS-65 & $223.1 \pm 2.7$ & $24.1 \pm 1.1$ & $22.75 \pm 0.85$ & $10.69 \pm 0.23$ \\
CAPS-66 & $205.3 \pm 0.6$ & $25.9 \pm 1.3$ & $25.56 \pm 0.85$ & $11.60 \pm 0.23$ \\
CAPS-67 & $266.0 \pm 4.4$ & $26.9 \pm 2.5$ & $30.53 \pm 1.73$ & $14.73 \pm 0.47$ \\
\hline
\end{tabular}

Results are expressed as mean value $\pm \mathrm{SD}$

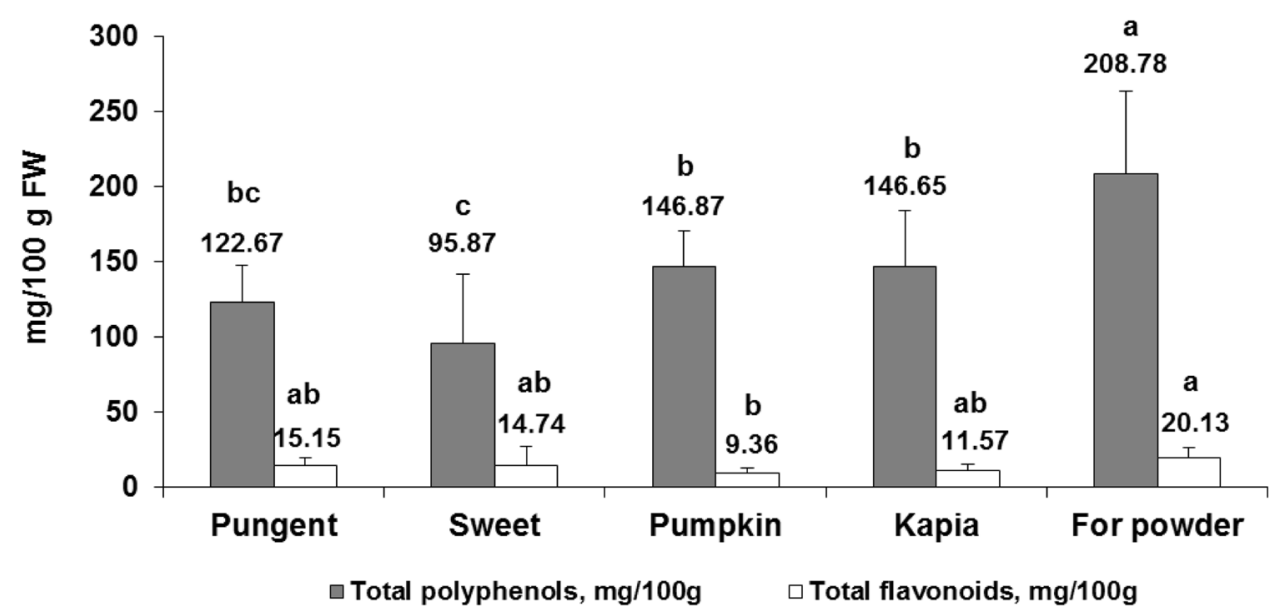

Fig. 5 ORAC and HORAC antioxidant activity of the studied groups. Results are expressed as mean value for the group \pm SD . There are no significant differences among values marked with the same letters in individual groups

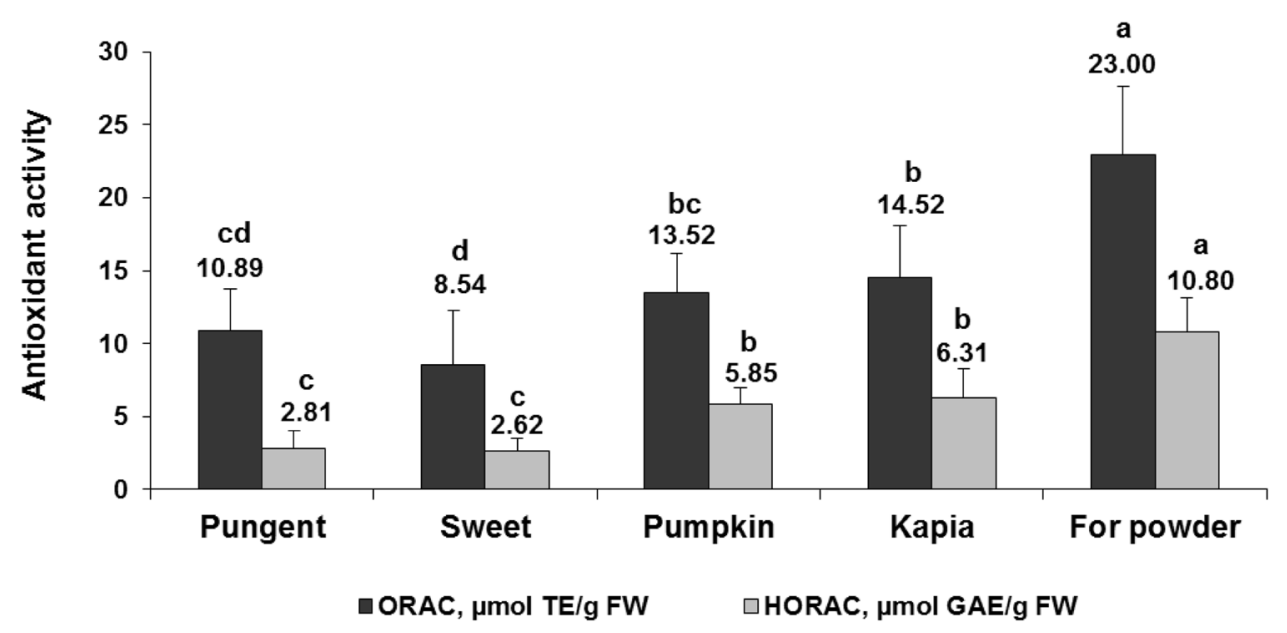




\section{Conclusion}

To our knowledge, the current study is the most comprehensive study on the phytochemical composition and antioxidant activity within the Balkan pepper (Capsicum annиит L.) germplasm collection. The obtained results show high variation in the composition profiles between the five pre-defined cultivar groups "Pungent", "Sweet", "Pumpkin", "Kapia" and "For powder". Complex characterization of the different genotypes adds valuable data when choosing parent forms, whereas the involvement of antioxidants-rich genotypes increase fruit quality and nutritional value of the future pepper varieties. Our study is essential also in relation to the preservation of pepper genetic diversity of the Balkan region, which is critical step in developing future varieties.

Acknowledgements The research leading to these results has received funding from the National Science Fund, Bulgaria [Grant DN06/4]. The authors VT, IT, SG and DK acknowledge the financial support by Horizon 2020 PlantaSYST project under Grant Agreement No 739582.

Funding This study was funded by the National Science Fund of Bulgaria [Grant DN06/4]. The authors VT, IT, SG and DK acknowledge the financial support by Horizon 2020 PlantaSYST project under Grant Agreement No 739582

\section{References}

1. FAO, The future of food and agriculture- - trends and challenges (FAO, 2017). https://www.fao.org/3/a-i6583e.pdf. Accessed 17 May 2019

2. B. Ou, D. Huang, M. Hampsch-Woodill, J.A. Flanagan, E.K. Deemer, J. Agric. Food Chem. 50, 3122 (2002)

3. I. Guzman, S. Hamby, J. Romero, P.W. Bosland, M.A. Oçonnell, Plant Sci. 179, 49 (2010)

4. S. Bogusz Jr., S.H. Libardi, F.F. Dias, J.P. Coutinho, V.C. Bochi, D.R. Arlete, M.T. Melo, H.T. Godoy, J. Sci. Food Agric. 98, 217 (2018)

5. C.J. Sandoval-Castro, M. Valdez-Morales, B.D. Oomah, R. Gutiérrez-Dorado, S. Medina-Godoy, L.G. Espinosa-Alonso, J. Food Sci. Technol. 54, 1999 (2017)

6. P.W. Bosland, E.J. Votava, Peppers: Vegetable and Spice Capsicums, 2nd edn. (CABI Publishing, New York, 2000), pp. 1-14

7. J.R. Stommel, E. Albrecht, in Peppers: Botany, Production and Uses, ed. by V.M. Russo (CAB International, Cambridge 2012) p. 29

8. L. Krasteva, Ts. Stoilova, K. Varbanova, St. Neykov, in European Landraces On-Farm Conservation, Management and Use, ed. by M. Veteläinen, V. Negri, N. Maxted N. (Bioversity International, Rome, 2009), p 53

9. Y. Wahyuni, A.-R. Ballester, E. Sudarmonowati, R.J. Bino, A.G. Bovy, Phytochem. 72, 1358 (2011)

10. W.Y. Liu, W.H. Kang, B.C. Kang, in Genetics, genomics and breeding of peppers and eggplants, ed. by B.-C. Kang, C. Kole (CRC Press Taylor and Francis Group, Boca Raton, 2013), p. 1

11. L.R. Howard, S.T. Talcott, C.H. Brenes, B. Villalon, J. Agric. Food Chem. 48, 1713 (2000)
12. M.H. Gnayfeed, H.G. Daood, P.A. Biacs, C.F. Alcaraz, J. Sci. Food Agr. 81, 1580 (2001)

13. J.L. Guil-Guerrero, C. Martinez-Guirado, M. Rebolloso-Fuentes, A. Carrique-Perez, Eur. Food Res. Technol. 224, 1 (2006)

14. N. Deepa, C. Kaur, B. George, B. Singh, H.C. Kapoor, LWTFood. Sci. Technol. 40, 121 (2007)

15. Y. Wahyuni, A.-R. Ballester, Y. Tikunov, R.C.H. de Vos, K.T.B. Pelgrom, A. Maharijaya, E. Sudarmonowati, R.J. Bino, A.G. Bovy, Metabolomics 9, 130 (2013)

16. IPGRI, AVRDC and CATIE, Descriptors for Capsicum (Capsicum spp) (International Plant Genetic Resources Institute, Rome, 1995), pp. 43-44

17. P. Denev, M. Kratchanova, I. Petrova, D. Klisurova, Y. Georgiev, M. Ognyanov, I. Yanakieva, J. Chem. 2018, Article ID 9574587, 13 pages (2018)

18. V. Singleton, J. Rossi, Am. J. Enol. Vitic. 16, 144 (1965)

19. C. Chang, M. Yang, H. Wen, J. Chern, J. Food Drug Anal. 10, 178 (2002)

20. A.E.R. Ahmed, J.M. Labavitch, J. Food Biochem. 1, 361 (1978)

21. N. Blumenkrantz, G. Asboe-Hansen, Anal. Biochem. 54, 484 (1973)

22. B. Ou, M. Hampsch-Woodill, R.L. Prior, J. Agric. Food Chem. 49, 4619 (2001)

23. P. Denev, M. Ciz, G. Ambrozova, A. Lojek, I. Yanakieva, M. Kratchanova, Food Chem. 123, 1055 (2010)

24. P.G. Acosta-Quezada, M.D. Raigón, T. Riofrío-Cuenca, M.D. García-Martínez, M. Plazas, J.I. Burneo, J.G. Figueroa, S. Vilanova, J. Prohens, Food Chem. 169, 327 (2015)

25. G. Corrado, M. Caramante, P. Piffanelli, R. Rao, Sci. Hortic. 168, $138(2014)$

26. A. Jamiołkowska, H. Buczkowska, A.H. Thanoon, Acta Sci. Pol. Hortorum Cultus 15, 95 (2016)

27. P. Luning, Characterisation of the Flavour of Fresh Bell Peppers (Capsicum annuum) and Its Changes After Hot-Air Drying: An Instrumental and Sensory Evaluation (Wageningen, Wageningen University Press, 1995), pp. 31-46

28. S. Osorio, R. Alba, Z. Nikoloski, A. Kochevenko, A.R. Fernie, J.J. Giovannoni, Plant Physiol. 159, 1713 (2012)

29. A.G.J. Voragen, W. Pilnik, J.-F. Thibault, M.A.V. Axelos, C.M.G.C. Renard, in Food Polysaccharides and Their Applications, ed. by A.M. Stephen (Marcel Dekker Inc, New York, 1995), p. 287

30. Y.N. Georgiev, M.H. Ognyanov, P.N. Denev, M.G. Kratchanova, in Handbook of Food Bioengineering, Therapeutic Foods, ed. by A.M. Holban, A.M. Grumezescu (Elsevier, Cambridge, 2018), p. 285

31. J. Lopez-Hernindez, M.J. Oruña-Concha, J. Simal-Lozano, M.E. Vázquez-Blanc, M.J. Gonzáilez-Castro, Food Chem. 57, 557 (1996)

32. R.L. Jarret, T. Berke, E.A. Baldwin, G.F. Antonious, Chem. Biodivers. 6, 138 (2009)

33. A.F. Molinari, L.R. Castro, S. Antoniali, P. Pornchaloempong, A.J. Fox, S.A. Sargent, E.M. Lamb, Proc. Florida State Hortic. Soc. p. 143 (1999)

34. M. Ghasemnezhad, M. Sherafati, G.A. Payvast, J. Funct. Foods 3, $44(2011)$

35. Food and Nutrition Board, Institute of Medicine, National Academies. Dietary Reference Intakes (DRIs): Recommended Dietary Allowances and Adequate Intakes, Vitamins. https://www.ncbi. nlm.nih.gov/books/NBK56068/table/summarytables.t2/?repor $\mathrm{t}=$ objectonly. Accessed 15 May 2019

36. L.R. Howard, R.E.C. Wildman, in Handbook of Nutraceuticals and Functional Foods, ed. by R.E.C. Wildman (CRC Press, Boca Raton, 2007) p. 165

37. S.A. Aliu, I. Rusinovci, S. Fetahu, S. Kaçiu, D. Zeka, Acta Agric. Slov. 109, 205 (2017) 
38. A.O. Kumar, S.S. Tata, Not. Sci. Biol. 1, 50 (2009)

39. A. Kołton, R. Wojciechowska, M. Leja, Veg. Crop Res. Bull. 74, $143(2011)$

40. V. Perla, P. Nimmakayala, M. Nadimi, S. Alaparthi, G.R. Hankins, A.W. Ebert, U.K. Reddy, Food Chem. 202, 189 (2016)

41. M. Naczk, F. Shahidi, J. Chromatogr. A 1054, 95 (2004)

42. A. Crozier, I.B. Jaganath, M.N. Clifford, in Plant Secondary Metabolites: Occurrence, Structure and Role in the Human Diet, ed. by A. Crozier, M.N. Clifford, H. Ashihara (Blackwell Publishing, Oxford, 2006), p. 1

43. P. Pietta, M. Minoggio, L. Bramati, in Studies in Natural Products Chemistry, ed. A. Rahman (Elsevier, Amsterdam, 2003) p. 257
44. R. Slimestad, M. Verheul, J. Sci. Food Agric. 89, 1255 (2009)

45. Y. Lee, L.R. Howard, B. Villalón, J. Food Sci. 60, 473 (1995)

46. A. Marín, F. Ferreres, F.A. Tomás-Barberán, M.I., Gil, J. Agric. Food Chem. 52, 3861 (2004)

47. M. Číž, H. Č́ížová, P. Denev, M. Kratchanova, A. Slavov, A. Lojek, Food Control 21, 518 (2010)

48. P. Denev, A. Lojek, M. Ciz, M. Kratchanova, Bulg. J. Agric. Sci. 19, 22 (2013)

49. P. Denev, M. Číž, M. Kratchanova, D. Blazheva, Food Chem. 284, 108 (2019) 